\title{
La evaluación docente como dispositivo de seducción. ¿Negarse también es resistir?
}

\author{
Alberto Galaz-Ruíz, Edgar-Daniel Anaya-Torres
}

\section{RESUMEN}

Este artículo realiza un análisis sobre la evaluación docente en tres momentos. El primero aborda una descripción histórico-política sobre sus antecedentes, articulaciones con organismos internacionales y políticas educativas en México y Chile. El segundo entrama un análisis hermenéutico que establece la relación del docente como sujeto de rendimiento, resultado de la evaluación e instrumentos específicos como: Perfiles, Parámetros e Indicadores (PPI) en México, y el Marco para la buena enseñanza (MBE), desde categorías enunciadas por Foucault y Han. Finalmente, en un tercer momento, se evidencian las grietas para repensar las subjetividades dentro del sistema educativo en general y el de la evaluación en particular.

Palabras clave: evaluación, docencia, política, subjetividad, poder y resistencia, México, Chile.

Edgar-Daniel Anaya-Torres Emprendedores San Martin Texmelucan, México. Temas de investigación: poder, educación, creatividad y precariedad laboral docente. ORCID: https://orcid.org/0000-0003-4879-2089.

\section{Alberto Galaz-Ruíz}

alberto.galaz@uach.cl

Chileno. Docteur en Sciences de la Education, Université de Rouen, Francia. Doctor en Educación, Pontificia Universidad Católica de Chile. Académico de la Facultad de Filosofía y Humanidades, Universidad Austral de Chile. Temas de investigación: identidad docente, subjetividades. ORCID: https://orcid.org/0000-0001-7729-2783. 


\title{
A avaliação docente como dispositivo de sedução. Negar-se também é resistir?
}

\section{RESUMO}

Este artigo realiza uma análise sobre a avaliação docente em três momentos. O primeiro aborda uma descrição histórico-política sobre seus antecedentes, articulações com organismos internacionais e políticas educativas no México e no Chile. O segundo entrama uma análise hermenêutica que estabelece a relação do docente como sujeito de rendimento, resultado da avaliação e instrumentos específicos como: Perfis, Parâmetros e Indicadores e o Marco para la buena enseñanza (MBE no Chile), desde categorias enunciadas por Foucault e Han. Finalmente, em um terceiro momento, se evidenciam as gretas para repensar as subjetividades dentro do sistema educativo em geral e da avaliação em particular.

Palavras chave: avaliação, docência, política, subjetividade, poder e resistência, México, Chile.

\section{Teacher evaluation as a seduction device: Is refusal also resistance?}

\begin{abstract}
This article analyzes teacher evaluation in three stages. The first one deals with a historical-political description of its antecedents, articulations with international organizations and educational policies in Mexico and Chile. The second one includes a hermeneutic analysis that establishes the relationship between the teacher as a subject of performance, the result of the evaluation and specific instruments such as profiles, parameters and indicators and the Framework for Good Teaching (Marco para la Buena Enseñanza, MBE in Chile), from categories enunciated by Foucault and Han. Finally, in a third moment, the gaps to rethink the subjectivities within the educational system in general and that of evaluation in particular are revealed.
\end{abstract}

Key words: evaluation, teaching, politics, subjectivity, power and resistance, Mexico, Chile. 


\section{Introducción}

El trabajo se divide en tres momentos. El primero traza un escenario histórico-político donde se construye la mecánica de acción mediante el concepto evaluación docente. Para el caso de México, se identifica el conjunto de instrumentos mediante la metodología de análisis de contenido, a través de la categoría evaluación docente, que van desde el marco normativo fundante, desprendido de la Reforma educativa de 2013 en la Ley General de Educación (LGE), la Ley del Servicio Profesional Docente (LGSPD), la Ley del Instituto Nacional para la Evaluación de la Educación (LINEE) y los organismos operativos como el Instituto Nacional para la Evaluación de la Educación (INEE), instrumentos como el Perfil, Parámetros e Indicadores (PPI), que contiene el prototipo sujeto-profesional docente que se busca instalar. Para el caso de Chile, el marco legal está dado por la Ley Orgánica Constitucional de Enseñanza (LOCE), la Ley General de Educación (LGE), programas como el de Mejoramiento de la Calidad y Equidad de la Educación (MECE), Reglamento de Evaluación y los organismos-instrumentos operativos establecidos como el Centro de Perfeccionamiento, Experimentación e Investigaciones Pedagógicas (CPEIP) y el Marco para la Buena Enseñanza (MBE).

El punto de encuentro de ambos países se da en las similitudes en políticas económicas y educativas, que se desarrollan desde 1980 hasta la actualidad; este corte transversal permitió la relación para la construcción del objeto de estudio, el hilo conductor es mediante la evaluación docente, así se establece el análisis de contenido sobre los documentos, los que son escogidos por las fuertes similitudes que tienen para ambos países.

El segundo momento tiene por objetivo develar cómo funciona el dispositivo de poder de la evaluación del desempeño docente en el sentido de la construcción de subjetividades y la forma en que se pretende lograr un sujeto idóneo, tanto para México como para Chile, para ello se usarán los documentos
PPI y MBE, los cuales son similares en ambos países. El marco metodológico es el análisis hermenéutico, mediante un corpus de categorías tales como biopoder, de la cual se desprende el concepto de cuerpos dóciles (Foucault, 2002, 2008, 2012) y psico poder. De este última desprendemos, a su vez, la noción de sujeto de rendimiento, propuesta por Han (2012, 2014 y 2016). El procedimiento se realizó mediante un constante cuestionamiento de los documentos oficiales desde las posturas teóricas, de tal manera que al usar las categorías se lograba generar interpretaciones de carácter crítico.

En el tercer momento se busca alumbrar un conjunto de espacios donde la des-sujeción del sujeto es posible, a partir de la identificación de puntos de fuga, grietas o estallidos, mediante una genealogía, lo cual permite abrir la posibilidad de que la reconstrucción de la educación y de la evaluación adquiera sentidos ajenos al sistema neoliberal que performa al sujeto, lo regula y le produce ser un sujeto de autoexplotación.

\section{Primer momento \\ Política histórica y contexto de evaluación}

Es socialmente compartido que la evaluación de los docentes es necesaria para asegurar la calidad profesional de quienes tienen la responsabilidad de lograr los aprendizajes de los estudiantes y evidenciar la eficiencia del sistema educativo. Lo social en este caso alude a quienes de una u otra forma tienen algún grado de relación y responsabilidad con el sistema escolar, es decir desde la autoridad político-educativa del país hasta la persona del propio profesor (Foucault, 2008: 33).

Sin embargo, no es común preguntarnos por el origen de los sistemas de evaluación y aún menos por los contenidos y supuestos que encierra esta representación. Aludimos a una representación en tanto construcción social e individual de un todo organizado de significados orientados a generar comprensión sobre determinados elementos de realidad, la 
identificación de quienes la comportan y la fundamentación de las acciones que se vislumbran (Abric, 1994). Bajo tal representación pareciera que dichos sistemas hubiesen tenido existencia eterna y, lo que es más interesante, que comportan el estatus o condición sine qua non de que todo intento o iniciativa de mejora de la educación se encuentra destinada al fracaso.

En este sentido, Popkewitz (1994) aludía a la naturaleza histórica de las reformas educativas a fin de esclarecer cómo bajo determinados intereses político-educativos el conjunto de sentidos conceptuales es difundido a manera de discursos unívocos que buscan no sólo aprehender la realidad sino también configurarla. En palabras de Fardella (2012) se trata de discursos que encierran "verdades" y "leyes de acción" y que poseen por objetivo establecer las coordenadas de "lo posible". Lo esencial de un discurso es que una vez traducido en acción político-social éste se asume incontestable, pareciera no tener alternativa, cuerpo ni temporalidad (Lechner, 2002). El actual discurso de la evaluación docente, enarbolado por organismos económicos internacionales y acogido por las autoridades político-educativas, se ha tejido bajo similares sentidos. Autoproclamado como desprovisto de todo interés ideológico se enclaustra en un campo de dominio técnico, abstracto, tomando distancia de las demandas y tradiciones profesionales de los docentes.

Pero la evaluación de los docentes ha gravitado bajo formas no exclusivas y se ha condicionado en su significado y alcances a las finalidades bajo las cuales han operado las reformas de los sistemas educacionales. Martinic (2001) y Suásnabar (2017) han identificado, a partir de coordenadas de cambio político, económico y social, que a fines de los años ochenta se evidencian signos de agotamiento de un ciclo educativo iniciado dos décadas atrás y caracterizado por reformas estructurales destinadas a fortalecer desde el Estado el acceso y la cobertura del sistema público de educación. El ciclo posterior será denominado reformas de segunda generación y marcarán, un punto de inflexión. En un nuevo escenario caracterizado por la creciente privatización e internacionalización del capital, aunado a una desconfianza absoluta en el aparato del Estado, el nuevo ciclo de reformas educativas pondrán su acento en la calidad y eficiencia de los diversos componentes del sistema educativo a fin de alinearlo convenientemente a las directrices del modelo económico, un proceso conocido como ajuste estructural e inicialmente impulsado por organismos internacionales como el Banco Mundial (BM) y el Fondo Monetario Internacional (FMI).

Los docentes y su evaluación también serán objeto de reforma. Desde una función socio-profesional que los identificaba como actores de la política de bienestar y funcionarios públicos del Estado (Núñez, 2007) y en donde la evaluación de su trabajo estaba orientada al ascenso en la carrera administrativa, en el nuevo ciclo serán concebidos como factores de rendimiento, por lo mismo evaluables o más bien medibles bajo enfoques de cuantificación y eficiencia, tomados de las apuestas evaluativas de autores tales como Tyler, Stake y Stuffebean (Escudero, 2003). En el nuevo discurso educativo y evaluativo desplegado, la profesionalidad y el desarrollo profesional de los docentes serán concebidos como requisitos indispensables, aunque paradójicamente se limite su autonomía bajo la lógica de la rendición de cuentas y la responsabilidad por los resultados (Baber y Mourshed, 2008; Hargreaves, 2003).

\section{La evaluación de los docentes chilenos y mexicanos}

Acudiendo a las coordenadas histórico-educativas enunciadas, Shulmeyer (2002) y Murillo (2006) confeccionaron un mapa más preciso de los sistemas de evaluación desarrollados y han concluido que en lo que respecta a América Latina la mayor parte de los países los han implementado. Concluyen además que no ha existido un solo enfoque de evaluación de los profesores ni que todos ellos comparten idéntico 
origen, supuestos o finalidad. Aunque recurriendo a coordenadas estructurales de definición tales como: enfoque de evaluación interno o externo a la escuela, finalidad orientada al desarrollo y ascenso profesional o más bien a incentivos y sanciones, es posible establecer ciertas tendencias.

Debido a sus definiciones y supuestos, a los intereses puestos por los gobiernos y organismos económicos internacionales pro-neoliberales en su desarrollo y, sobre todo, por las resistencias que han generado en los docentes ahí donde se han instalado, nuestro foco de análisis lo hemos dirigido a los sistemas de evaluación de la docencia que desde fines de los años noventa desarrollaron Chile y México. Nos referimos en particular a sistemas de evaluación concebidos en el marco de principios y categorías tales como calidad y eficiencia, que son propias de las reformas educativas de segunda generación; de sistemas que en su dimensión político-educativa se articularon con el marco de principios que sustentan las medidas económicas de ajuste estructural y que, en un contexto de creciente globalización, internacionalización económica, privatización de los servicios de Estado, han buscado alinear sistemas y actores educativos a intereses políticos y económicos transnacionales (Ball, 2009).

Nos referimos a dos sistemas de evaluación que poseen en común la identificación del profesor y su desempeño como factores fundamentales, cuando no exclusivos, de la eficiencia del sistema educativo, incluso por sobre otros como el origen socioeconómico de los alumnos y sus familias, el tipo de gestión y provisión del servicio educativo, la autonomía y los recursos otorgados a las escuelas y la infraestructura disponible, etcétera. (Cornejo y Redondo 2007; Murillo y Román, 2011; Criollo-Vargas et al., 2020). Se trata de sistemas de evaluación que se conciben externos a dicho desempeño; que para fines de medición y control sistematizan y simplifican dicho desempeño en marcos estandarizados (dimensiones e indicadores) de actuación y que, en función de la identidad profesional oficialmente promovida, también establecen qué es aquello más o menos importante de evaluar.

Por sobre una concepción colectiva o comunitaria del desarrollo y mejora escolar, el énfasis de estos sistemas ha estado puesto en la rendición de cuentas individual. Por lo mismo, las consecuencias del resultado de evaluación final obtenido tienen idéntico impacto, ya sea asociado a avances en la carrera profesional o en su forma más extrema al despido. La evaluación se concibe como un asunto de orden técnico y por lo mismo de responsabilidad de instituciones y expertos privados o públicos designados para dicho fin. En el caso de México la reforma educativa del 2013 atribuye dicha responsabilidad al Instituto Nacional para la Evaluación de la Educación (INEE) y en Chile al Centro de Perfeccionamiento e Investigaciones Pedagógicas (CPEIP), aunque en el despliegue técnico que significa la elaboración de los instrumentos y el desarrollo, las evaluaciones son delegadas en instituciones privadas contratadas para dicho fin. En Chile corresponde a Docente más de la Universidad Católica y en específico a su Facultad de Psicología (Manzi, González y Yun, 2011) y en el caso de México al Centro Nacional de Evaluación para la Educación Superior (CENEVAL). El empleo de sofisticados instrumentos y complejos sistemas de análisis estadísticos es otra dimensión constitutiva. También se recurre a instrumentos cualitativos tales como observaciones o entrevistas, reportes de directivos, pero se les asigna escaso valor o ponderación.

\section{El docente en la evaluación}

La posición y función otorgadas al profesor en el organigrama de la evaluación es un factor definitorio del carácter que asume. En algunos sistemas educativos que han servido de referencia internacional en materia de resultados educativos (Hong Kong, Shanghái, Singapur, Finlandia, etcétera) la evaluación es un asunto de la escuela, de sus profesores, alumnos e incluso de los padres o, en su defecto, dentro de un 
marco preestablecido de regulaciones a nivel central, ellos poseen importantes márgenes de acción y autonomía. En el extremo opuesto se encuentran los sistemas que definen a las escuelas en tanto centros de aplicación de los instrumentos y a sus profesores como respondientes.

La evaluación de la docencia en Chile y México se encuentra dentro de éstos últimos. En ambos países los docentes no están considerados como parte de la gestión central del proceso. En el organigrama de planeación del proceso evaluativo ocupan como cuerpo profesional una posición terminal. Esto a pesar de que algunos docentes sean convocados y contratados a conformar parte de equipos elaboradores de ítems, aplicadores y/o correctores de los instrumentos, pero se trata de una actuación a título personal y, como señaláramos, bajo la dependencia de organismos contratados por el Estado para dicho fin.

Pero la elección de un modelo de evaluación guarda relación no sólo con los fines e intereses generales puestos sobre los sistemas educativos, sino particularmente con la confianza que se deposita en la labor de los docentes. En esta línea existe suficiente evidencia respecto a cómo esta confianza social traducida por ejemplo en reconocimiento y autonomía, opera como un mecanismo potenciador del compromiso, la pertenencia, la autoestima y el sentimiento de autoeficacia (Day, 2011; Guevara, Meléndez, Ramón, Sánchez y Tirado, 2016).

En los estudios y reportes oficiales de la evaluación docente de México y Chile es posible notar como estas dimensiones son obviadas en función de la identificación del resultado de desempeño como leitmotiv del sistema (Reglamento de Evaluación 192; Reforma al artículo $3^{\circ}$, fracción IX, de la Constitución Política de los Estados Unidos Mexicanos, 2013). No se espera que los profesores participen activamente en el diseño o ejecución de la evaluación, tampoco se proyecta abrir espacios o generar condiciones para que ello ocurra. Se espera lisa y llanamente que los profesores se evalúen y asuman las consecuencias de sus resultados. Desde esta perspectiva es posible concebir que el docente es representado en tanto sujeto evaluable bajo el supuesto del control externo de sus acciones, de la reducción del sentido colectivo de la pedagogía a la acción individual y de la ausencia de sentidos o significados culturales arraigados históricamente en las escuelas, como resultado de las prácticas sociales que allí se desarrollan.

A pesar de sus evidentes implicaciones, la subjetividad de los profesores no ha sido un ámbito profusamente abordado o fundamentado por aquellos expertos o investigadores que orbitan en el campo de gravedad de estos sistemas. Tampoco ha formado parte de los informes oficiales de las instituciones responsables de la evaluación en ambos países, ni tampoco de los diagnósticos que organismos nacionales e internacionales han realizado de estos sistemas. Al respecto, es ilustrativo revisar los reportes anuales que emite el CPEIP en Chile sobre los resultados de la evaluación docente (CPEIP, 2019) y en México el Informe de Supervisión de la Evaluación del Desempeño Docente en educación básica y media superior en el ciclo escolar 2016-2017 (INEE, 2018).

Pero la discusión sobre la subjetividad en dichos sistemas resulta interesante, no sólo porque involucra adentrarse en el complejo campo de las definiciones y oposiciones, sino también porque permite retirar su velo de falsa naturalidad y verificar la relativa estabilidad de las posiciones teóricas y políticas que la sostienen. Con ello queremos advertir que tanto la subjetividad (del profesor) como la cotidianidad (el tiempo-espacio permanente e incesante de construcción y despliegue de las acciones) son campos de referencia ineludible y por lo mismo en permanente disputa (Cornejo, Albornoz y Palacios, 2016). No hay política ni construcción de lo social sin sujetos o sin relación a la subjetividad. Más allá de lo aparente, señala Lechner (2002), lo que hoy vivenciamos es una forma de política que parece haber perdido o más bien abandonado su dimensión subjetiva en función de asumirse como un campo técnico de 
acción, distante de la cotidianidad. El interés de fondo de tal postura encierra un doble propósito. Por una parte, eludir las evidentes implicaciones de acción política que encierra la subjetividad y por otra parte, inmovilizar.

\section{Segundo momento \\ Entramado teórico de la evaluación}

El biopoder es una categoría encargada de exponer la sujeción del cuerpo, la objetivación de las actividades de los cuerpos dóciles pensados en funciones activas dentro de la sociedad, puesto que no son entidades pasivas en espera de órdenes; más bien, son entidades autorreguladas que responden a multivariables y propósitos propios del sistema social (Foucault, 1999, 2002 y 2008). Esto es, el disciplinamiento del cuerpo forma una tecnología que encuentra su base en la vigilancia; así, el concepto en forma metafórica del panóptico de Bentham funciona (Foucault, 2002), puesto que se puede observar a todos dentro de las instituciones, dígase prisión, escuela, manicomios, donde se disciplinan, se vigilan y se castigan (Foucault, 2002).

Aquí el poder tiene una función de coerción a través de la disciplina que se impone a los cuerpos, de tal manera que las conductas y las actitudes observables se adaptan constantemente a las formas y las transformaciones que las instituciones tienen, dependiendo de los paradigmas, modelos económicos, políticos y sociales, los cuales se diversifican dependiendo del contexto, de los momentos históricos; esto permite pensar que las formas de dominaciones cambian o más bien se amplían, se adaptan, se modulan a las condiciones y los cambios sociales (Abeijón, 2014; Deleuze, 2016; Foucault, 2002).

Para Foucault existe una diversificación del poder que se desarrolla al momento de tratar de luchar contra él, esto es que:

Esta forma de poder se ejerce sobre la vida cotidiana inmediata que clasifica a los individuos en categorías, los designa por su propia individualidad, los ata a su propia identidad, les impone una ley de verdad que deben reconocer y que los otros deben reconocer en ellos. Es una forma de poder que transforma a los individuos en sujetos (Foucault, 1988: 7).

La evaluación del desempeño docente es el dispositivo de poder que instrumentaliza dicho disciplinamiento sobre los cuerpos dóciles del docente dentro de la institución escuela, puesto que sistematiza una forma para ser así en el mundo que proviene del exterior y no de la tensión dialéctica entre el sujeto y los otros; se le dota de una clasificación que denota si el sujeto es idóneo o no idóneo, como menciona Galaz, en "un juego de espejos rotos" (2015), donde lejos de reconocerse a través de la evaluación, se somete a ella como un requerimiento social e institucional para mantener su trabajo y que su rol social no se vea desacreditado a través de cumplir un conjunto de competencias docentes (Ramos-Zincke, 2018).

La evaluación funge como un dispositivo de poder el cual es un conjunto multifacético que contiene discursos, instituciones, lugares, regulaciones, administración de recursos, establecimiento de ideales, leyes, procedimientos, enunciados científicos y filosóficos, incluso lo no mencionado (Agamben, 2011).

\section{El prototipo de profesor de rendimiento mediante el PPI y el MBE}

Para Han (2012), existe una transición entre el deber hacer y el querer hacer, donde la libertad es el punto base de su razonamiento en torno al sometimiento del sujeto, puesto que no piensa en la idea de coerción del poder, más bien, en la idea de seducción e invitación del poder, donde el sujeto es inducido a actuar por sí mismo como si fuese un proyecto personal, a reproducir la inercia y las formas del poder (Han, 2012 y 2016).

Esto significa que deja de pensar en el sujeto oprimido para pensar en el sujeto de rendimiento, "La sociedad del siglo XXI ya no es disciplinaria, sino 
una sociedad de rendimiento. Tampoco sus habitantes se llaman ya «sujetos de obediencia», sino «sujetos de rendimiento»" (Han, 2012: 16).

Así se indica que el poder camina desde un conjunto de elementos represivos y de prohibiciones a un conjunto de elementos de rendimiento, esto no significa que el sujeto disciplinar ha dejado de existir, significa que el poder aumenta el nivel de productividad obtenida por una lógica técnico-disciplinar y por el imperativo del deber. En relación con el incremento de productividad se asiste una continuidad entre del deber y el poder (Han, 2012).

Esto se procura mediante una ilusión, el profesorsujeto cree que es responsable de sí, ante sí y para sí de los resultados obtenidos en la evaluación del desempeño docente y de los alumnos, sin lograr ver las coerciones o seducciones que el modelo pone en acción (Anaya, 2019). Este argumento sobre el poder tiene una fuerte ejemplificación con la calidad educativa, promovida por el modelo, entendida como la suma de los resultados individuales, que generan narrativas que los docentes interiorizan, lo cual produce que él asume la responsabilidad total de los resultados del rendimiento de sus alumnos y no cómo el juego de múltiples factores, sin embargo, no en una visión solo represiva, más bien seductora, que increpa un individualismo y atomización para lograr metas y planes que parecen personales, basados en las habilidades que es deseable tener para cumplir con el trabajo docente; esto resulta en las dimensiones observadas en los dispositivos e instrumentos que tiene el sistema de evaluación del desempeño docente, pero particularmente en el PPI para el caso México y los dominios que presenta el MBE para el caso de Chile, un perfil deseable que a su vez se diversifica en parámetros y da un conjunto de indicadores que acompañan la medición del sujeto. Hay que hacer explícito que tanto la evaluación docente como estos elementos de caracterización trabajan al unísono ya que:
El poder inteligente, amable, no opera de frente contra la voluntad de los sujetos sometidos, sino que dirige esa voluntad a su favor. Es más afirmativo que negador, más seductor que represor. Se esfuerza en generar emociones positivas y en explotarlas. Seduce en lugar de prohibir. No se enfrenta al sujeto, le da facilidades (Han, 2014: 29).

La invitación al sometimiento desprendida del modelo neoliberal, que piensa Han (2014), se introdujo en un sinnúmero de pautas, se propone seguir al sujeto de rendimiento (docente idóneo) y, a través de elementos como el avance en la carrera magisterial, tanto en Chile como en México, muestra las formas donde él es sujetado y premiado puesto que: "el sujeto de rendimiento neoliberal, ese empresario de sí mismo, se explota de forma voluntaria y apasionada" (Han, 2014: 45).

Esta idea de empresario de sí queda plasmada en el caso de Chile, con la invitación que realiza el dispositivo de evaluación a evidenciar las deficiencias del desempeño y a mejorarlas sobre la base de la responsabilidad individual, por medio de las oportunidades de mejora o desempeño personal que puede tomar el profesor o profesora; mediante una capacitación constante con un conjunto de elementos que otorga el mismo sistema para mejorar particularmente, en la ilusión que el profesor-sujeto tiene el control y la posibilidad de obtener mejoras en los resultados.

Para generar este andamio se piensa en las tecnologías del yo y no en las tecnologías del poder, puesto que:

tecnologías del yo, que permiten a los individuos efectuar, por cuenta propia o con la ayuda de otros, cierto número de operaciones sobre su cuerpo y su alma, pensamientos, conducta, o cualquier forma de ser, obteniendo así una transformación de sí mismos con el fin de alcanzar cierto estado de felicidad, pureza, sabiduría o inmortalidad (Foucault, 2008: 48). 
La necesidad de tender un enlace que se mueva, que se adapte y que permita la constante sujeción del sujeto, es lo que le da un conjunto de componentes narrativos y discursivos para que el docente se entienda, se conduzca, se defina y aprenda de sí mismo, lo que ejerce una relación del sujeto con los demás (Foucault, 2008). Así, mediante el PPI y el MBE, se observa una tecnología del yo, que permite tener un sujeto al que se le impone un conjunto de ideales a cumplir, primordialmente habilidades, competencias; el PPI enuncia:

El perfil que se presenta a continuación expresa las características, cualidades y aptitudes deseables que el personal docente y técnico docente requiere tener para un desempeño profesional eficaz; además de ser una guía que permita a maestras y maestros orientar su formación para desempeñar un determinado puesto o función en el sistema de Educación Básica (SEP, 2015: 12).

\section{Para el caso de Chile, el MBE propone:}

El diseño de los criterios muestra los elementos específicos en los que deben centrarse los profesores. El hilo conductor o unificador que recorre todo el Marco consiste en involucrar a todos los alumnos en el aprendizaje de contenidos importantes. Todos los criterios del Marco están orientados a servir a este propósito básico (CPEIP, 2003: 7).

Las formas en las que se reconoce y objetiva, en otras palabras, deviene sujeto mediante una categorización a través de un conjunto de parámetros a cumplir, para lograr ser considerado profesor idóneo, donde se muestran elementos de diversificación, medición y jerarquización lo cual, sometidos a las estructuras sociales, pero también a las situaciones, momento-espacio, tanto de la sociedad, como del sujeto, para que las conveniencias del poder se ejerzan (Deleuze, 2016; Foucault, 2005).
Las tecnologías del yo sirven como puente para entender cómo se genera la producción del yo, su uso y sus procesos, esto es que: "nuevas tecnologías de subjetivación, resultado de la expansión por el cuerpo social de diferentes dispositivos de poder, configuran individuos que se autorregulan y autogobiernan" (Santiago, 2017: 326).

El deseo de transitar de cuerpos dóciles a conciencias autorregulables, a partir de pautas sistematizadas, donde el sujeto asuma como parte de su proyecto personal la voluntad del opresor, es un lado de la sujeción y su constante adaptabilidad a las exigencias de la estructura social, sin embargo, por sí mismos los PPI y el MBE son sólo ideal del sujeto que se desea y puede ser mantenido, sin embargo, se necesita de un dispositivo que permita la mecanización del ideal tipo, la cual es la evaluación del desempeño docente, puesto que funciona como un gobierno de conductas.

\section{Tercer momento}

\section{Grietas y resistencias a la evaluación}

A la luz de nuestras adhesiones epistemológicas y pedagógicas, pero así también en el reconocimiento de las experiencias más creativas y participativas de evaluación de la docencia, estimamos que el profesor no es un sujeto bajo control absoluto o por lo mismo sujetado-asido desde y por las estructuras. En tanto actores pueden subjetivar su experiencia, construir significados, dar sentido a sus acciones e incluso abrir márgenes de acción para recrear sus propias lógicas y crear acuerdos (Ketelaar et al., 2012).

Tal adhesión nos parece pertinente a fin de abordar analíticamente la complejidad de las resistencias que los profesores chilenos y mexicanos han desarrollado sobre su evaluación. Esto supone entenderlas desde el punto de vista de la defensa de significados y tradiciones colectivas y no, como se pretende hacer creer oficialmente, como un malestar "atendible" o como reacciones conservadoras. Aunque desde el punto de vista de la autoridad es comprensible no quererlo hacer en función del riesgo que 
compromete. La discusión de fondo, por cierto, alude a una política y a un sistema diseñado de forma externa a las escuelas pero que busca desplegarse en ellas sin la necesaria consideración de su historia o cultura. El conflicto a nuestro juicio es inevitable.

Vargas (2012) analiza dicha noción desde el punto de vista de las ciencias sociales y concuerda en que dentro la polisemia que la acompaña, existe un punto de acuerdo en situarla dentro de las relaciones históricas de dominación cultural. Un aspecto clave en su significado es que en tanto oposición al status quo su origen se explica en el reconocimiento por un colectivo de su identidad y de una dignidad que ha sido violentada simbólica u objetivamente. Pero es esta oposición la que hace posible desnaturalizar la fuente de poder de la autoridad que la infringe.

Otra dimensión que resulta interesante es aquella que refiere la existencia de una forma de resistencia pasiva y otra activa. La resistencia pasiva acoge acciones de preservación de la cultura y de solidaridad con el colectivo, no necesariamente evidentes para la autoridad. La activa por una parte se expresa en la pública movilización social y, por otra, en el desarrollo de prácticas contrahegemónicas.

Visto así, el énfasis puesto por las autoridades educativas chilenas y mexicanas en el éxito de las medidas destinadas a instaurar una cultura evaluativa (como si las escuelas no la hubiesen tenido), traducida por ejemplo en la reducción del número de profesores que se niegan (o resisten) a evaluarse, no sólo es reduccionista sino también errónea. Es reduccionista porque concibe la resistencia como negación y errónea en tanto dicha reducción se explica por medidas de fuerza que no atiende, el problema de base, la crisis de legitimidad de la evaluación. En el caso de Chile esto ha sido particularmente evidente. Se ha atribuido al decreto 20501 de 2011, que facultó de forma extraordinaria a los sostenedores y directores de escuela a despedir a los profesores con resultado insatisfactorios, como factor determinante en la reducción de un 10.5\% $(\mathrm{n}=14$ 190) en 2006 al $0.5 \%(\mathrm{n}=20259)$ de profesores que se niega a evaluar (CPEIP, 2019). Otras formas de resistencia son invisibilizadas. En el caso de México se reportan en diversos estados importantes ausencias para el proceso de evaluación 2015 que convocó a un total 150000 profesores. Así también se da cuenta de las amenazas de despido por parte de la autoridad educativa. Otras formas de resistencia también han sido invisibilizadas (Díaz-Barriga, 2015; Cedillo, 2017; Gómez, 2017).

Autores como Sánchez y Corte (2015) han abordado dichas resistencias y han concluido que en su origen ellas se explican por el enfoque de diseño y la falta de flexibilidad de estos sistemas para acoger el sentir y los saberes que se construyen en la escuela. Con base en estos hallazgos es posible identificar que otras condiciones específicas, tales como el tiempo excesivo y no siempre otorgado que demandan, la inexistencia de condiciones propicias para asistir y responder, la falta de información, la complejidad de los instrumentos, la radicalidad de sus consecuencias, entre otras y aquellas asociadas al exacerbado carácter individual, la estigmatización que genera sus resultados, el débil reconocimiento y la escasa pertinencia de las oportunidades de desarrollo profesional, son factores gatillantes de las resistencias de los profesores.

Pero otras formas de resistencia activa también han sido reportadas a nivel internacional. Woods (2002) reporta cómo ante los procesos evaluativos resultantes de la reforma educacional de Inglaterra los maestros simulaban ante los supervisores la realización de aquellas prácticas o acciones demandadas para luego retomar aquellas que desarrollaban de forma tradicional. Galaz (2015) y Anaya (2019) reportan que, ante el agobio y falta de reconocimiento inherente a la evaluación, los profesores chilenos planeaban abandonar la profesión, situación recurrente sobre todo en aquellos docentes con vasta trayectoria. Por su parte Galaz (2019) reportan en su estudio comparativo, formas de resistencia de los 
docentes mexicanos y chilenos frente al individualismo, la soledad y el estrés que conlleva su evaluación, el desarrollo de acciones de solidaridad, apoyo y trabajo colegiado.

\section{Conclusiones}

La evaluación docente que hemos analizado para el caso de México y Chile alimenta el individualismo como expresión de la máxima libertad del sujeto que se opone a toda forma de colectividad, pero en la escuela y en otros espacios lo que se promueve es la colectividad incluso por el modelo mismo. Se expresa en la reflexión colectiva y el trabajo colaborativo de profesores, en búsqueda de una comunidad educativa y de aprendizaje; ésta es una paradoja del propio sistema, puesto que en la evaluación las coordenadas apuntan a la responsabilidad individual y la autogestión, de conocimientos, habilidades, aptitudes, actitudes y competencias que recaen en el sujeto. Por otro lado, se pide que exista el trabajo colaborativo dentro de la vida cotidiana de los docentes, dicha paradoja plantea problemas en los imaginarios y en las formas de acción del docente.

La evaluación como un dispositivo de poder genera una ilusión de mejora a partir de estar enmarcado en el contexto de calidad educativa, esto tiene una relación directa con la subjetividad de los docentes, puesto que trasciende la práctica y las formas de relación social. En otras palabras, se construye una subjetividad alrededor del sujeto para que las prácticas desprendidas del modelo neoliberal en educación sean normalizadas, no es este aparato el único que se encarga del proceso de subjetivación, sin embargo, es el que instrumentaliza las formas y los procesos en la realidad social.

En el devenir histórico contextual político de la primera parte se explicita la forma de acción del modelo neoliberal en educación, que va desde los organismos internacionales y se internaliza mediante políticas educativas en los diferentes países como México y Chile. La maquinaria que se acciona es de alta eficiencia y aquí se relaciona con la idea del poder, puesto que es una forma de sometimiento seductor, crea un prototipo de sujeto como el que refiere Byung Chul Han el empresario de sí o sujetos de rendimiento, aquel que se autoexplota y piensa que su voluntad es libre y única para lograr metas autoimpuestas.

La conclusión general invita a pensar que el sistema de evaluación en sí mismo tiene grietas y fracturas en sus procesos, un ejemplo de ellas son las resistencias de los docentes al momento de ser evaluados, las cuales en lugar de pensarse como errores que se pueden mejorar, más bien debían pensarse como posibilidades de puntos de fuga para reconstruir el sistema educativo en la generalidad y en la inmediatez, repensar el proceso de evaluación de profesores y alumnos, para cambiar las coordenadas que observen al sujeto fuera del mercado de trabajo o el mercado como propulsor de realidad y centrarlo en las necesidades de aprendizaje enseñanza de estudiantes y profesores. 


\section{Referencias}

Abeijón, M. (2014), "El poder y el sujeto. Sujeción, norma y resistencia en Judith Butler", en Michel Foucault: más allá del estructuralismo y la hermenéutica, La Plata, Editorial Universidad de la Plata, pp. 97-114.

Abric, J. (1994), Pratiques sociales et représentations, París, Presses Universitaires de France.

Agamben, G. (1977), "Qué es un dispositivo”, Sociológica, vol. 26, núm. 73, pp. 155-163.

Anaya-Torres, E. (2019), "Calidad educativa como precarización laboral: análisis de América Latina", Revista Latinoamericana de Estudios Educativos, vol. XLIX, núm. 2, pp. 9-34, <http://www.redalyc.org/articulo. oa?id $=27059273004>$.

Ball, S. (2009), "Privatising education, privatising education policy, privatising educational research: network governance and the competition state", fournal of Education Policy, vol. 1, núm. 24, pp. 83-99.

Barber, M. y M. Mourshed (2008), Cómo hicieron los sistemas educativos con mejor desempeño del mundo para alcanzar sus objetivos, Documento 41, Chile, PREAL.

Cedillo-Arias, L. (2017), "Retos del INEE ante la evaluación docente. Docencia y evaluación en la Reforma Educativa 2013", México, IISUE-UNAM, pp. 2, <http://132.248.192.241:8080/jspui/bitstream/ IISUE_UNAM/207/1/Retos\%20del\%20INEE $\% 20$ ante $\% 201 \mathrm{la} \% 20$ evaluaci $\% \mathrm{C} 3 \% \mathrm{~B} 3 \mathrm{n} \% 20$ docente.pdf>.

Centro de Perfeccionamiento Educativo e Investigaciones Pedagógicas (CPEIP) (2003), Marco para la Buena Enseñanza, Chile, CPEIP, Ministerio de Educación, DOI: https://doi.org/10.1017/ CBO9781107415324.004.

CPEIP (2019), Resultados de Evaluación Docente, Chile, CPEIP, Ministerio de Educación, <https://www. cpeip.cl/evaluacion-docente/resultados-evaluaciondocente-2018/>.

Constitución Política de los Estados Unidos Mexicanos (2013) Reglamento de Evaluación $\mathcal{N}^{\circ} 192$, Reforma al artículo $3^{\circ}$, fracción IX.

Cornejo, R., N. Albornoz y D. Palacios (2016),
"Subjetividad, realidad y discurso entre el determinismo estructuralista y el construccionismo social", Cinta Moebio, vol. 56, pp. 121-135, DOI: 10.4067/S0717$554 X 2016000200001$.

Cornejo, R. y J. Redondo (2007), "Variables y factores asociados al aprendizaje escolar. Una discusión desde la investigación actual”, Estudios Pedagógicos, vol. 3, núm. 2, pp. 155-175, DOI: 10.4067/S071807052007000200009.

Criollo-Vargas, M., R. Moreno-Ordoñez, B. Ramon y A. Cango-Patiño (2020), "Factores familiares, comunitarios y escolares que influyen en el rendimiento académico de los estudiantes", Polo del Conocimiento, vol. 5, núm. 41, pp. 622-646, <https://www.polodelconocimiento.com/>.

Day, C. (2011), Pasión por enseñar: La identidad personal y profesional del docente y sus valores, Madrid, Narcea.

Deleuze, G. (2016), Foucault, México, Paidós.

Díaz-Barriga, Á. (2015), "Despedir docentes por no presentarse a la evaluación, ¿algo que festejar?”, Nexos, 18 de noviembre, <https://educacion.nexos.com.mx/ despedir-docentes-por-no-presentarse-a-la-evaluacionalgo-que-festejar/>.

Escudero, T. (2003), "Desde los tests hasta la investigación evaluativa actual. Un siglo, el XX, de intenso desarrollo de la evaluación en educación”, Relieve, vol. 9, núm. 1, pp. 11-43, <http://www.uv.es/RELIEVE/v9n1/ RELIEVEv9n1_1.htm>.

Fardella, C. (2012), "Verdades sobre la docencia, efectos y consecuencias subjetivas de la evaluación docente en Chile", Revista de Psicología, vol. 21, núm. 1, pp. 209227, DOI: 10.5354/0719-0581.2012.19996, <https:// revistapsicologia.uchile.cl/index.php/RDP/article/ view/19996>.

Foucault, M. (2012), El poder, una bestia magnifica: Sobre el poder, la prisión y la vida, Buenos Aires, Siglo XXI Editores, <http://www.sigloxxieditores.com.ar/pdfs/ foucault_el_poder_una_bestia_magnifica.pdf $>$.

Foucault, M. (2008), Tecnologías del yo y otros textos afines, Buenos Aires, Paidós. 
Foucault, M. (2005), El orden del discurso, Buenos Aires, Tusquets Editores.

Foucault, M. (2002), Vigilar y castigar: nacimiento de la prisión, Buenos Aires, Siglo XXI Editores.

Foucault, M. (1999), Estética, ética y hermenéutica. Obras esenciales, Volumen 3, Barcelona, Paidós.

Foucault, M. (1988), "El sujeto y el poder", Revista Mexicana de Sociología, vol. 50, núm. 3, pp. 3-20, jul-sep, <http://links. jstor.org/sici? $\mathrm{sici}=01882503 \% 28198807 \% 2 \mathrm{~F} 09 \% 2950 \%$ 3A3\%3C3\%3AESYEP $\% 3 \mathrm{E} 2.0 . \mathrm{CO} \% 3 \mathrm{~B} 2-\mathrm{A}>$.

Galaz, A. (2015), "Evaluación e identidad profesional del profesor ¿Un juego de espejos rotos?", Andamios, vol. 12, núm. 27, pp. 305-333, <http://www.redalyc. org/pdf/628/62841659015.pdf>.

Galaz, A., Á. Díaz-Barriga y M. Jiménez-Vásquez (2019), "Evaluación del desempeño docente en Chile y México", Perfiles Educativos, vol. 41, núm. 163, pp. 156-176, DOI: https://doi.org/10.22201/ iisue.24486167e.2019.163.58935.

Gómez, A. (2017), "Evaluación docente en escuelas de educación básica en Colima", Pensamiento Educativo, vol. 1, núm. 54, pp. 1-18.

Guevara, G., M. Meléndez, F. Castaño, H. Sánchez y F. Tirado (2016), La evaluación docente en el mundo, México, Fondo de Cultura Económica.

Han, B. (2016), Sobre el poder, Barcelona, Herder.

Han, B. (2014), Psicopolítica Neoliberalismo y nuevas técnicas de poder, Barcelona, Herder.

Han, B. (2012), La sociedad del cansancio, Barcelona, Herder.

Hargreaves, A. (2003), Enseñar en la sociedad del conocimiento, Barcelona, Octaedro.

Instituto Nacional de Evaluación Educativa (INEE) (2018), "Informe de supervisión de la Evaluación del Desempeño Docente en educación básica y media superior en el ciclo escolar 2016-2017", México, INEE, <https://www.inee. edu.mx/publicaciones/informe-de-supervision-de-laevaluacion-del-desempeno-docente-en-educacion-basicay-media-superior-en-el-ciclo-escolar-2016-2017/>.

Ketelaar, E., B. Douwe, B. Henny y D. Brok (2012), "Teachers' positioning towards an educational innovation in the light of ownership, sense-making and agency",
Teaching and Teacher Education, vol. 28, núm. 2, pp. 273-282. Lechner, N. (2002), Las sombras del mañana. La dimensión subjetiva de la politica, Santiago de Chile, LOM Editores.

Manzi, J., R. González y Y. Sun (2011), La evaluación docente en Chile, Santiago de Chile, MIDE UC, <https://www. mideuc.cl/libroed/pdf/La_Evaluacion_Docente_en_ Chile.pdf $>$.

Martinic, S. (2001), "Conflictos políticos e interacciones comunicativas en las reformas educativas en América Latina", Revista Iberoamericana de educación, núm. 27, pp .1733, <https://rieoei.org/historico/documentos/rie27a01. $\mathrm{PDF}>$.

Murillo, J. (2006), Evaluación y carrera docente: una panorámica de América y Europa, Santiago de Chile, UNESCO.

Murillo, J. y M. Román (2011), “¿La escuela o la cuna? Evidencias sobre su aportación al rendimiento de los estudiantes de América Latina. Estudio multinivel sobre la estimación de los efectos escolares", Profesorado. Revista de Curriculum y Formación del profesorado, vol. 15, núm. 3, pp. 27-50, <http://www.ugr.es/ recfpro/ rev153ART3.pdf>.

Núñez, I. (2007), "La profesión docente en Chile. Saberes e Identidades en su Historia". Pensamiento Educativo, vol. 41, núm. 2, pp 149-164.

Popkewitz, T. (1994), "Política, conocimiento y poder: algunas cuestiones para el estudio de las reformas educativas", Revista de Educación, núm. 305, pp. 103137, <https://dialnet.unirioja.es/servlet/articulo? codigo $=19037>$.

Ramos-Zincke, C. (2018), "Dispositivo de evaluación y gubernamentalidad del sistema educacional: entretejimiento de ciencia social y poder", Cinta de Moebio, núm. 61, pp. 41-55, DOI: https://doi. org/10.4067/S0717-554X2018000100041

Sánchez-Cerón, M. y F. Corte-Cruz (2015), "La evaluación a la docencia. Algunas consecuencias para América Latina", Revista Mexicana de Investigación Educativa, vol. 20, núm. 67, pp. 1233-1253, <http:// www.scielo.org.mx/scielo.php? script $=$ sci_arttext\&pid $=$ S1405-66662015000400011>.

Santiago, A. (2017), "La sociedad de control: una mirada 
a la educación del siglo XXI desde Foucault", Revista de Filosofia, vol. 73, pp. 317-336, DOI: https://doi. org/10.4067/s0718-43602017000100317.

Secretaria de Educación Pública (SEP) (2015), Perfil, parámetros e indicadores para docentes y técnicos docentes, México, SEP, <https://issuu.com/gabrielvitalroman/ docs/perfil_desempeno_docente_tecdocente>.

Shulmeyer, A. (2002), "Estado actual de la evaluación docente en trece países de América Latina", Trabajo presentado en la Conferencia Regional, El desempeño de los maestros en América Latina y el Caribe: nuevas prioridades, Brasilia, 10-12 de julio.
Suásnabar, C. (2017), "Los ciclos de reforma educativa en América Latina: 1960, 1990 y 2000", Revista Española de Educación Comparada, núm. 30, pp. 112-135.

Vargas, J. (2012), "A propósito de la resistencia como propuesta teórica del estudio histórico", Tiempo y espacio, vol. 28, pp. 7-22, <http://revistas.ubiobio.cl/ index.php/TYE/article/view/1791/1735>.

Woods, P. y B. Jeffrey (2002), "The reconstruction of primary teachers' identities", British Journal of Sociology of Education, vol. 23, núm. 1, pp. 89-106, DOI: 10.1080/01425690120102872.

\section{Cómo citar este artículo:}

Galaz-Ruíz, Alberto y Edgar-Daniel (2022), “La evaluación docente como dispositivo de seducción. ¿Negarse también es resistir?”, Revista Iberoamericana de Educación Superior (RIES), vol.XIII, núm. 36, pp. 124-137, DOI: https://doi.org/10.22201/iisue.20072872e.2022.36.1187 [Consulta: fecha de última consulta]. 